\title{
Procedimiento Penal Inmediato para el Delito de Feminicidio: Caso Bolivia
}

\author{
Immediate criminal Procedure for the crime of femicide: Case \\ Bolivia
}

\author{
Estefanía Suárez La Fuente \\ estefania.suarez299@gmail.com \\ Universidad Andina Simón Bolívar, Bolivia
}

Recibido octubre 2018; arbitrado noviembre 2018; y publicado enero 2019

\begin{abstract}
RESUMEN
ABSTRACT

La problemática de la violencia contra la mujer es un fenómeno que alarma a toda la sociedad, y lo que es peor, se tornó en un fenómeno en constante crecimiento, al no contar Bolivia con una normativa legal procesal eficiente y efectiva. El objetivo principal fue proponer un procedimiento penal inmediato, efectivo y sumario para los casos de feminicidio. La metodología estuvo orientada bajo el paradigma cuantitativo, el método empleado fue de análisis - síntesis y descriptivo de la información. Como resultados se establecido que lo más óptimo es la aplicación de un procedimiento inmediato, expedito, sumario y efectivo en delitos de feminicidio en los siguientes casos: Primero, cuando haya existido una relación de afectividad o intimidad, sea ésta con el cónyuge, conviviente, enamoramiento o en relación de pareja y se demuestre, por cualquier medio, que haya existido cualquier tipo de violencia previa, sin necesidad de sentencia ejecutoriada y segundo, cuando hayan mantenido relaciones sexuales

The problem of violence against women is a phenomenon that alarms the whole of society, and what is worse, it became a phenomenon in constant growth, not counting Bolivia with an efficient and effective procedural legal regulation. The main objective was to propose an immediate, effective and summary criminal procedure for femicide cases. The methodology was oriented under the quantitative paradigm, the method used was of analysis - synthesis and descriptive of the information. As a result, it is established that the best is the application of an immediate, expeditious, summary and effective procedure in Femicide crimes in the following cases: first, when there has been a relationship of affection or intimacy, be it with the spouse, cohabiting, falling in love or in relationship with each other, and it is demonstrated, by any means, that any type of previous violence has existed, without the need for enforceable sentence and second, when they have had consent or not previously sexual relations to the fact.
\end{abstract} consentidas o no previamente al hecho.

Palabras clave: Feminicidio; procedimientos penales; normativa boliviana

Key words: femicide; Criminal proceedings; Bolivian regulations 


\section{INTRODUCCIÓN}

Este estudio estuvo enmarcado en la problemática de la violencia contra la mujer viendo que este es un fenómeno que alarma a toda la sociedad, y lo que es peor, se torna en constante crecimiento, al no contar Bolivia con una normativa legal procesal eficiente y efectiva destinada a mitigar esta vicio social, menos lograr soluciones objetivas a dicho problema.

En el ámbito internacional se han previsto distintos instrumentos para tratar la temática, ya sea para prevenirla, ya sea para castigarla; de la misma manera, en el ámbito internacional y las legislaciones nacionales se han ocupado de la temática cada quién de acuerdo a su forma de encarar el problema y su modo de proceder.

En Bolivia se ha promulgado la Ley № 348 de 9 de marzo de 2013 con la finalidad de garantizar a la mujer una vida libre de violencia especificando que cuando se trate de un proceso penal por violencia contra la mujer, éste debe ser aplicado con mucha atención y de manera especial, por las implicancias sociales de este tipo de conductas antijurídicas.

Lamentablemente hoy por hoy, quienes conocen y trabajan en el tema, pueden advertir que no se cuenta con un procedimiento especial en los delitos por violencia contra la mujer y mucho menos en casos de feminicidios, puesto que, a pesar que los tutelados e incluso algunos operadores de justicia, tienen la falsa creencia o convicción que contamos con un procedimiento especial, pues, al contrario, las mujeres y víctimas más sus abogados defensores peregrinan en el procedimiento penal común que resulta ser un proceso lleno de revictimización, largo, caro y en el que en muy pocas ocasiones, encuentran una solución.

Es por eso que en la presente investigación pretendió, a partir del análisis de la normativa y teoría existente sobre el tema, más las opiniones y experiencias de quienes conocen $\mathrm{y}$ trabajan en el tema, proponer un procedimiento penal especial para el delito de feminicidio tipificado la legislación penal en Bolivia, pero que se aplique solo cuando concurran determinadas circunstancias acontecidas tanto previamente como a momento de cometer el feminicidio.

Para finalizar este estudio buscó lograr que las víctimas de un feminicidio en dos determinadas circunstancias, no se vean impedidas o limitadas de proseguir el proceso penal por el hecho de saber que el procedimiento es engorroso y que nunca llegará a una solución restitutiva a pesar de lo latente de sus lesiones.

\section{Importancia del Problema}

El proceso actualmente vigente para los casos de feminicidios en Bolivia se encuentra previsto en la Ley № 348 de 9 de marzo de 2013, el mismo que se aplica cuando se trata de casos en los que exista entre agresor y víctima una relación de afectividad $\mathrm{y}$ concurren las siguientes circunstancias:

- PRIMERO: Que se demuestre que la víctima ya había denunciado previamente por violencia al agresor, $\mathrm{y}$

- SEGUNDO: En los casos en que se evidencia signos de agresión sexual previa al hecho.

No obstante la citada Ley No. 348, resulta que se aplica el mismo procedimiento penal común, para los casos de feminicidios, esto hace que el procedimiento no sea efectivo y $(\mathrm{y}$ que generalmente no concluya el caso conse una sentencia) mucho menos se llegue a una sentencia $y$ mucho menos se arribe necesariamente a una sentencia, quedando los procesos truncados por abandono, frente a la pesadez del sistema y la tremenda carga procesal de los jueces. 


\section{METODOLOGÍA}

El tipo de investigación que se utilizó se caracteriza por ser cualitativa y el método empleado es el análisis - síntesis y el descriptivo. En primer término, se realizó un análisis del procedimiento actual que se usa en los procesos por violencia para llegar a una síntesis y compararlo con la propuesta planteada acerca de la "Propuesta De Procedimiento Inmediato Para Delitos De Feminicidio". De la misma manera se elaboró una descripción de lo que se tiene como procedimiento y por medio de las técnicas de observación y entrevistas, se analizaron y describieron el estado actual de los procesos de investigación en etapa preparatoria y juzgamiento oral de este delito, en base a observación propia, opiniones y propuestas de expertos y operadores de justicia, entendidos en el tema, ubicando dónde se encuentran las fallas en el proceso penal por feminicidio; con esta descripción se propone un procedimiento penal especial para este tipo de casos de violencia contra las mujeres.

\section{RESULTADOS Y DISCUSIÓN}

\section{Propósito}

Como ya lo se ha señalado en esta investigación, a partir del sistema internacional de defensa, protección y promoción de los derechos humanos, existen diversos instrumentos internacionales para la protección de las mujeres en cuanto a actos de violencia en su contra.

A su vez, la Constitución Política del Estado Plurinacional de Bolivia ha adoptado estos instrumentos y derechos y los ha constitucionalizado, normativas que dan cuenta de la importancia, necesidad y justifican la creación y aplicación de procedimientos especiales cuando se trata de la violación de los derechos de las mujeres, especialmente si se trata del delito de feminicidio.
Finalmente, se ha creado en Bolivia una ley específica que crea delitos y les da un trato especial a los mismos, con el fin de prevenir, perseguir y sancionar, una Ley que es integral y que está orientada a garantizar a las mujeres una vida libre de violencia, la Ley № 348 .

Específicamente en lo que se refiere al delito de feminicidio, cual es el tema central de esta investigación, se ha podido verificar que, a pesar de contar con todos estos instrumentos normativos, en la práctica no se está aplicando la ley, que esta ley no es aplicable por distintas falencias y motivos; se está reproduciendo aún la impunidad en el delito de feminicidio puesto que no se está castigando de manera pronta y correcta su comisión.

Las entrevistas a las personas y sujetos procesales del delito de feminicidio nos dan cuenta que existen muchas falencias sobre muchos temas, las mismas que, de manera general, quedando citada así:

- Falta de especialización de los investigadores, fiscales, peritos, jueces, personal alterno y abogados;

- Ausencia, y en algunos casos y lugares, falta total de personal en fiscalía, juzgados, órganos investigadores y de estudios forenses;

- Toma excesiva de tiempo para elaboración de actos investigativos, señalamiento de audiencias, asistencia de las partes y emisión de resolución conclusiva fiscal;

- Excesiva actitud dilatoria por parte de los abogados de la defensa de manera desleal $\mathrm{y}$ actos faltos de ética que influyen en el resultado del proceso;

- Solicitud innecesaria de recursos de reposición o de apelación por parte de los litigantes en el proceso;

- Fijación de audiencias con mucho tiempo de distancia entre ellas, debido a la alta carga procesal de jueces y magistrados;

- Fijación de audiencias nominales; 
- Suspensión de audiencias por inasistencia, primordialmente de los abogados de la defensa y luego por la inasistencia del fiscal;

- Exceso de ritualismos en el trámite de distintos actos investigativos $\mathrm{y}$ de producción de prueba en el juicio.

Ante estas falencias, y siendo que el delito de feminicidio se lleva a cabo como un procedimiento común en todos los casos, cuando incluso se encuentra identificada a la persona con mayor probabilidad de ser el autor del hecho, lo que se ha pensado como necesario, es un procedimiento más ágil e inmediato en dos casos en específico, como lo señalamos y se reitera en la investigación, en los que un hombre haya dado muerte a una mujer.

\section{Exposición de motivos}

Respecto a los instrumentos internacionales tenemos:

1. Que la Convención sobre la Eliminación de Todas las Formas de Discriminación contra la Mujer - CEDAW, ratificada por Bolivia mediante Ley № 1100 de 1989 y su Protocolo Facultativo, también ratificado mediante Ley № 2103 del año 2000, establecen la urgencia de modificar los roles tradicionales de los hombres y las mujeres en la sociedad y la familia. De la misma manera, hace responsable a los Estados por la discriminación que sufren las mujeres, tanto en la esfera pública como en la esfera privada;

2. Que la Declaración sobre la Eliminación de la Violencia Contra la Mujer de 1993, define la violencia contra las mujeres y la reconoce como una forma de discriminación que constituye una manifestación de las relaciones de poder históricamente desiguales entre hombres y mujeres, debiendo los Estados establecer, en la legislación nacional, sanciones penales, civiles, laborales $\mathrm{y}$ administrativas, para castigar y reparar la violencia contra las mujeres;

3. Que la Convención Interamericana para Prevenir, Sancionar y Erradicar la Violencia Contra las Mujeres, (la Convención Belem do Pará), ratificada por Bolivia mediante Ley № 1599 de 1994, establece las obligaciones de los Estados de actuar con la debida diligencia para prevenir, investigar y sancionar la violencia contra la mujer e incluir en su legislación interna normas para prevenir, sancionar y erradicar la violencia contra la mujer, entre otras;

4. Que el Estatuto de Roma, de la Corte Penal Internacional, ratificado por Bolivia mediante Ley № 2398 de 2002 reconoce y califica a la violencia contra las mujeres, así como la violación y otras agresiones sexuales, como delitos de lesa humanidad;

5. Que el Comité de Derechos Humanos, en su Observación General No. 18, ha señalado medidas especiales para luchar contra la violencia contra la mujer, medidas de ese carácter que pueden llegar hasta otorgar, durante un tiempo al sector de la población de que se trate, un cierto trato preferencial en cuestiones concretas, en comparación con el resto de la población, sin embargo, en cuanto son necesarias para corregir la discriminación de hecho, esas medidas son una diferenciación legítima con arreglo al Pacto de San José de Costa Rica.

6. Que el Comité para la Eliminación de la Discriminación Contra la Mujer, en la Recomendación General No 25 explica y concluye que la aplicación de medidas especiales de carácter temporal de conformidad con la Convención, están destinadas a lograr la igualdad sustantiva de la mujer, que es un medio de hacer realidad la igualdad sustantiva o de facto de la mujer y no una excepción a las normas de no discriminación e igualdad; 
añadiendo que las medidas especiales de carácter temporal deberán adoptarse para acelerar la modificación y la eliminación de prácticas culturales y actitudes y comportamientos estereotípicos que discriminan a la mujer o la sitúan en posición de desventaja;

7. Que en base a los Arts. 410 y 256. I. de la Constitución Política del Estado se debe aplicar preferentemente los tratados internacionales de derechos humanos que garantizan los derechos de las mujeres a no sufrir violencia, cuando su formulación fuera más favorable que los contenidos constitucionales;

8. Que la Constitución Política del Estado en relación a la violencia contra las mujeres ha incluido en el Art. 15 el reconocimiento de los derechos a la vida y a la integridad física, psicológica y sexual señalando que el Estado adoptará las medidas necesarias para prevenir, eliminar y sancionar la violencia de género y generacional, así como toda acción u omisión que tenga por objeto degradar la condición humana, causar muerte, dolor y sufrimiento físico, sexual o psicológico, tanto en el ámbito público como privado;

9. Que en fecha 9 de marzo de 2013 se ha promulgado la Ley Integral Para Garantizar a la Mujer una Vida Libre de Violencia, Ley № 348 que busca prevenir, perseguir y condenar cualquier forma de violencia en contra de la mujer, así como crea el tipo penal de feminicidio y lo incluye en la normativa penal en el Art. 252 bis del Código Penal.

\section{Procedimiento Inmediato para Delitos de Feminicidio}

Artículo 1. (Ámbito de aplicación). Este procedimiento se encuentra reservado para los casos en lo que un hombre: a) Mate a una mujer con la que haya tenido una relación de afectividad o intimidad, sea esta cónyuge, conviviente, enamoramiento o de relación de pareja y se demuestre por cualquier medio que haya existido cualquier tipo de violencia previa, sin necesidad de sentencia ejecutoriada.

b) Mate a una mujer con la que haya mantenido relaciones sexuales consentidas o no previamente al hecho.

En ambos casos, deberá existir evidencia conducente e indicios suficientes sobre la existencia del hecho y la participación del imputado en él.

Artículo 2. (Procedencia). En la resolución de imputación formal, el fiscal solicitará al juez de instrucción la aplicación del procedimiento inmediato para delitos de feminicidio conforme a las normas del presente Título, cuando concurran las circunstancias previstas en el Art. 1.

Una vez conocido el hecho, el fiscal deberá emitir la imputación formal en un plazo no mayor a 48 horas y solicitar la audiencia en el mismo plazo.

Artículo 3. (Audiencia primera). El juez está obligado a fijar la audiencia primera en el plazo de 24 horas. En audiencia oral, el juez de instrucción escuchará al fiscal, al imputado y su defensor, a la víctima o al querellante, verificará el cumplimiento de las condiciones de procedencia previstas en el Artículo precedente y resolverá sobre la aplicación del procedimiento en la misma audiencia.

Asimismo, en la misma audiencia, si el juez acepta la aplicación del procedimiento inmediato por feminicidio, el fiscal podrá:

1. Solicitar el procedimiento abreviado cuando concurran los requisitos previstos en este Código;

2. $\mathrm{Si}$ requiere realizar actos de investigación o de recuperación de 
evidencia complementarios, solicitará al juez el plazo que considere necesario, que no podrá exceder de diez (10) días. El juez resolverá sobre el pedido del fiscal;

3. Si considera que cuenta con suficientes elementos de convicción, presentará la acusación y ofrecerá la prueba en la misma audiencia. El querellante podrá adherirse a la acusación del fiscal o acusar particularmente en la misma audiencia y ofrecerá su prueba de cargo. La acusación pública, y en su caso la acusación particular, se pondrán en conocimiento del imputado en la misma audiencia, para que en el plazo máximo de cinco (3) días ofrezca su prueba de descargo. Vencido este plazo, inmediatamente el juez de instrucción señalará día y hora de audiencia de juicio oral, mismo que se realizará dentro de los tres (5) días siguientes, sin excepción.

4. Solicitar la detención preventiva del imputado, cuando concurra alguno de los requisitos establecidos en el Artículo 233 del presente Código, para garantizar su presencia en el juicio. La solicitud no podrá ser denegada por el juez de instrucción, salvo los casos de improcedencia de la detención preventiva.

5. Las resoluciones dictadas en esta audiencia primera, no serán susceptibles de recurso alguno.

\section{Artículo 4. (Audiencia de Excepciones y} de preparación de juicio). La audiencia de excepciones durará una sola sesión y las partes podrán:

Observar la acusación fiscal o particular por defectos formales, requiriendo su corrección;

1. Deducir excepciones y otros medios de defensa, el juez podrá rechazar in limine cuando verifique que las excepciones o incidentes que sean excesivas $y$ dilatorias, sin recurso ulterior;

2. Plantear incidentes de exclusión probatoria u observaciones a la admisibilidad de la prueba, a cuyo efecto las partes deberán presentar la prueba documental y material ofrecida en la acusación, el juez podrá rechazar in limine cuando verifique las exclusiones que sean excesivas $y$ dilatorias, sin recurso ulterior;

3. El juez dispondrá los hechos sobre los que versará el debate de juicio. Finalizada la audiencia, el juez de instrucción resolverá inmediatamente todas las cuestiones planteadas, salvo que por lo avanzado de la hora o lo complejo de los asuntos por resolver difiera la fundamentación de la decisión hasta por veinticuatro (24) horas improrrogables. Las decisiones sobre la admisibilidad de prueba y las exclusiones probatorias no son recurribles.

4. En la misma resolución sobre las cuestiones planteadas, el juez de instrucción dictará auto de apertura de juicio, disponiendo la remisión de la acusación pública y particular, el escrito de ofrecimiento de la defensa y las pruebas documentales y materiales ofrecidas al Tribunal de Sentencia en un plazo máximo de cuarenta y ocho (48) horas improrrogables.

Artículo 5. (Remisión, sorteo) La remisión y el sorteo de la causa no podrá exceder del plazo de veinticuatro horas (24 Hrs.) y no podrán rechazar o prorrogar este plazo por bajo ninguna circunstancia, mucho menos por una de forma.

Artículo 6. (Radicatoria) Radicada la causa, el tribunal de sentencia señalará día y hora de audiencia de sustanciación del 
juicio, que se realizará en un plazo no mayor a cinco (5) días. En el mismo señalamiento de la audiencia de juicio, el tribunal de sentencia, para prever el correcto desarrollo de esta audiencia dispondrá que se convoque a defensa pública o abogado de oficio, alertando a la defensa que la inasistencia de su abogado defensor no suspenderá dicho actuado. De la misma manera se alertará a la acusación particular, o a la víctima que su inasistencia no determinarán una suspensión de audiencia.

Artículo 7. (Audiencia de Juicio Oral) El día y hora de audiencia, verificada la presencia de las partes, el juez concederá la palabra a la Fiscalía para que realice la fundamentación de su acusación; posteriormente, dará la palabra al acusador particular para que fundamente su acusación y a la víctima si lo solicita; luego al imputado a los efectos de saber si hará uso en ese momento de su defensa material y finalmente otorgará la palabra a la defensa técnica para que presente su caso. No se dará lectura a las acusaciones ni al ofrecimiento de prueba de la defensa. Abierto el debate, se recibirá la prueba del Ministerio Público, luego la prueba de la acusación particular y finalmente la prueba de la defensa, en el orden en que cada parte considere conveniente para su presentación. No se dará lectura a las pruebas documentales y de las periciales solo se dará lectura de sus conclusiones.

Si el imputado decide declarar como parte de la prueba de la defensa, éste será tratado de acuerdo a las reglas de declaración de testigos en juicio oral.

Finalizada la producción de la prueba, cada parte, comenzando por el Ministerio Público, tendrá la oportunidad de realizar su alegato en conclusiones, dando en última instancia la palabra a la víctima y al imputado, en ese orden, a los efectos de que puedan realizar su manifestación final.

No se aplicará la réplica y la dúplica.

En todo lo demás serán aplicables las reglas previstas para el juicio ordinario, conforme a lo señalado en este Código.

Artículo 8. (Sentencia). Finalizados los alegatos de las partes, el juez de sentencia procederá a dictar sentencia inmediatamente, conforme a lo previsto en los Artículos 361 y siguientes de este Código, sin embargo, no se podrá diferir la redacción de los fundamentos, debiendo darse lectura íntegra de la misma.

En caso de dictar sentencia condenatoria, el juez se encuentra obligado a argumentar su fallo en base al Protocolo Para Juzgar Con Perspectiva de Género.

Artículo 9. (Defensa técnica). El tribunal de sentencia deberá conminar a que en todas las audiencias se presente un abogado de defensa pública o de oficio con el fin de que éstas no se suspendan.

El plazo de diez días calendario dispuestos por el Art. 104 de este Código queda prohibido.

Artículo 10. (Prohibición de recurso de reposición). El recurso de reposición previsto en el Art. 401 de este Código se encuentra prohibido en el juicio oral, sin perjuicio de reservase del derecho de apelación restringida.

Artículo 11. (Prohibición de excepciones e incidentes). Se encuentra totalmente prohibido interponer excepciones o incidentes en esta etapa del proceso. 
Artículo 12. (Prohibición de plazo para defensa técnica). Se encuentra totalmente prohibido interponer excepciones o incidentes en esta etapa del proceso.

\section{Artículo 13. (Prohibición de suspensión} de audiencias y reanudación de audiencia). Las audiencias no se suspenderán por inasistencia del abogado de la defensa estando en su lugar el abogado de defensa pública o de oficio.

Tampoco se podrán suspender por inasistencia del representante del Ministerio Público, teniendo el juez que declarar un cuarto intermedio en el mismo día para que éste se haga presente por el lapso de algunos minutos y horas en su caso.

La audiencia no se suspenderá por inasistencia de la acusación particular ni de la víctima.

La inasistencia de un perito o testigo no suspenderá la audiencia, pudiendo el juez disponer de un cuarto intermedio en el mismo día para que éste se haga presente.

La audiencia no se suspenderá por falta de un juez técnico, existiendo quórum con dos jueces técnicos.

La reanudación de la audiencia deberá hacerse al día siguiente indefectiblemente.

Se encuentra prohibido disponer audiencias nominales.

Artículo 14. (Prohibición de amenazas y de procesos). Durante la prosecución del proceso, el imputado queda totalmente prohibido de ejercer amenazas en contra de la víctima ya sea por sus familiares, por terceros o por sí mismo, asimismo, queda totalmente prohibido a ejercer amenazas a todos los familiares de la víctima o terceros relacionados con ella.
De la misma manera, queda totalmente prohibido iniciar cualquier tipo de proceso, sea este penal o de cualquier materia en contra de la víctima, familiares suyos o terceros relacionados con ella, ya sea por sí mismo, por sus familiares o terceros.

Ante la simple denuncia de una amenaza o de un proceso en su contra, la víctima podrá poner en conocimiento del juez de instrucción o del tribunal de sentencia, teniendo éste que llamar severamente la atención a la defensa y tomar este antecedente como prueba en el proceso.

\section{CONCLUSIONES}

Como se ha podido denotar existe una preocupación actual e inminente con relación a la muerte de las mujeres que se producen como una manera de aplicación y mantenimiento de las formas de poder que algunos hombres han adquirido con el paso de los años y que se traducen hoy en misoginia; estas relaciones de poder están marcadas por el machismo que nace de un sistema patriarcal de la sociedad en la que actualmente vivimos. Dicha preocupación ha sido plasmada en los distintos instrumentos internacionales que se han nombrado, así como en las leyes bolivianas, por lo que en otros países se encuentran sumando esfuerzo por buscar maneras de prevenir, perseguir y sancionar el delito de feminicidio. A pesar de ello, lo cierto es que es menester cuestionarnos de manera constante y ser críticos para verificar si es que dichas leyes están siendo efectivas, y si es que no lo están siendo, es una obligación buscar nuevas maneras de combatir la emergencia de las muertes de mujeres por el delito de feminicidio.

Se ha podido verificar que está justificada y permitida la aplicación de medidas especiales y de emergencia por parte de los Estados cuando el problema ataca a un sector 
vulnerable de la sociedad, un sector que requiere especial atención cuando el fenómeno social así lo requiere; las muertes de mujeres por razones de género son un sector de la sociedad que necesita toda nuestra atención en este momento, así como un procedimiento eficaz de persecución para no dar cabida a la impunidad.

También la violencia se ha acrecentado en Bolivia, con la perpetración del delito de feminicidio en contra de las mujeres, así como del resultado de las entrevistas y la aplicación de la técnica de la observación practicada ha dado muestra fiel de que el procedimiento de feminicidio, tanto en las etapas de investigación como su juzgamiento en Bolivia, el cual se desarrolla como un delito cualquiera, con el procedimiento penal ordinario, es engorroso, está lleno de dilaciones innecesarias, dura demasiado tiempo y pocas veces se llega a una sentencia por el mismo paso del tiempo así como por la ineficacia de los operadores o administradores de justicia.

Además, se analizó la legislación vigente en Bolivia y se ha verificado que ante la inexistencia de un procedimiento especial para el delito de feminicidio, es necesaria la aplicación de un procedimiento especial, un procedimiento que sea eficiente y que en definitiva sea inmediato en los casos en los que se hace totalmente evidente quién lo ha cometido, todo esto para no caer en la impunidad y en el desapego a la ley por el capricho y falta a la ética profesional de algunos abogados defensores, que en base a pruebas falsas buscan extender los procesos perjudicando el descubrimiento de la verdad de los hechos, elemento fundamental para lograr la equidad, en base al descubrimiento de la verdad jurídica en cada caso.

Por los que se estableció que lo más óptimo es la aplicación de un procedimiento inmediato, expedito, sumario y efectivo en delitos de feminicidio en los siguientes casos: Primero, cuando haya existido una relación de afectividad o intimidad, sea ésta con el cónyuge, conviviente, enamoramiento o en relación de pareja y se demuestre, por cualquier medio, que haya existido cualquier tipo de violencia previa, sin necesidad de sentencia ejecutoriada y segundo, cuando hayan mantenido relaciones sexuales consentidas o no previamente al hecho.

\section{REFERENCIAS}

CEDAW. Organización de las Naciones Unidas. (s.f.). UN.ORG. disponible en: http://www.un.org/womenwatch/daw/c edaw/recommendations/General\%20rec ommendation $\% 2025 \% 20$ (Spanish).pdf

Corte Interamericana de Derechos Humanos. (16 de NOVIEMBRE de 2009). CORTEIDH. Recuperado el 10 de FEBRERO de 2019, de

http://www.corteidh.or.cr/docs/casos/ar ticulos/seriec_205_esp.pdf

Gaceta Oficial de Bolivia. (2009). Constitución Política del Estado Plurinacional de Bolivia . La Paz, Bolivia.

Gaceta Oficial de Bolivia. (1999). Código de Procedimiento Penal de Bolivia Ley № 1970. La Paz, Bolivia.

Gaceta Oficial de Bolivia. (1997). Código Penal Ley № 1768. La Paz, Bolivia.

Gaceta Oficial de Bolivia. (2013). $L E Y$ INTEGRAL PARA GARANTIZAR A LAS MUJERES UNA VIDA LIBRE DE VIOLENCIA Ley NNo 348. La Paz, Bolivia.

Organización de Estados Americanos - OEA. (9 de JUNIO de 1994). OAS.ORG. Recuperado el 10 de FEBRERO de 2019, de http://www.oas.org/juridico/spanish/tra tados/a-61.html

Órgano Judicial - Comité de Género. (2017). Protocolo para Juzgar con Perspectiva de Género (Segunda Ed.). Chuquisaca Bolivia: Omar Cornejo Orellana.

Observatorio de Igualdad y Género de América Latina y el Caribe. (2017). CEPAL. Recuperado el enero de 2019, de https://oig.cepal.org/es/indicadores/fem inicidio

Tribunal Constitucional Plurinacional. (18 de SEPTIEMBRE de 2014). Revista Boliviana de Derecho. Recuperado el 10 de FEBRERO de 2019, de 
http://www.revistabolivianadederecho.c om/index.php/item/2041-scp-02602014-aia-12-02.

UNICEF. (2017). Comunicación, Infancia y Adolescencia. Guía para periodistas.
Perspectiva de Género. (1era edición ed.). Buenos Aires, Argentina: GOMO. 